\title{
Image-based study of marginal bone loss in teeth restored with cast endodontic posts
}

\author{
Perda óssea marginal em dentes restaurados com pinos \\ endodônicos: estudo baseado em imagem
}

Sandro Luiz FARIAS ${ }^{1}$ iD 0000-0002-8092-4259

Milena Bortolloto Felippe SILVA ${ }^{2}$

Rielson José Alves CARDOSO' ${ }^{1}$ iD 0000-0002-5239-1301

Marcelo SPERANDIO3 ${ }^{3}$ iD 0000-0003-3836-1891

\section{ABSTRACT}

The aim of this study was to assess marginal bone loss in teeth restored with endodontic posts on all four aspects of the teeth using cone beam tomography. Bone loss was assessed via scores (0-5) in relation to root length and bone height. The results showed that the scores for the contralateral and restored sides, respectively, ranged from 0 to 3 and 0 to 5 buccally, 0 to 4 and 0 to 4 palatally, 0 to 3 and 0 and 4 mesially and 0 to 3 and 0 to 4 distally. A significant difference in bone loss was observed between the post-restored teeth and their contralaterals for the buccal, lingual/palatal and mesial aspects $(p<0.05)$, with teeth bearing endodontic posts scoring highest. In conclusion, marginal bone loss was higher in teeth restored with intra-canal posts when compared to their sound contralaterals.

Indexing terms: Cone beam computed tomography. Endodontics. Periodontal disease.

\section{RESUMO}

O objetivo deste estudo foi avaliar a perda óssea marginal nas quatro faces de dentes restaurados com pinos endodônticos, usando tomografia por feixe cônico. A perda óssea foi avaliada através de escores (0-5) em relação ao comprimento da raiz e altura do osso. Os resultados mostraram que os escores dos lados contralateral e restaurado, respectivamente, variaram de 0 a 3 e 0 a 5 bucalmente, 0 a 4 e 0 a 4 palatalmente, 0 a 3 e 0 e 4 mesialmente e 0 a 3 e 0 a 4 distalmente. Uma diferença significativa na perda óssea foi observada entre os dentes pós-restaurados e seus contralaterais para os aspectos vestibular, lingual / palatal e mesial ( $p<0,05)$, com os dentes com pinos endodônticos pontuando mais alto. Em conclusão, a perda óssea marginal foi maior em dentes restaurados com pinos intra-canal quando comparados aos seus contralaterais sonoros.

Termos de indexação: Tomografia computadorizada de feixe cônico. Endodontia. Doenças periodontais.

\section{$\boldsymbol{\nabla v} \mathbf{v}$}

${ }^{1}$ Faculdade São Leopoldo Mandic, Instituto de Pesquisas São Leopoldo Mandic, Área de Endodontia. Campinas, SP, Brasil.

2 Faculdade São Leopoldo Mandic, Instituto de Pesquisas São Leopoldo Mandic, Área de Radiologia Odontológica. Campinas, SP, Brasil.

${ }^{3}$ Faculdade São Leopoldo Mandic, Instituto de Pesquisas São Leopoldo Mandic, Área de Patologia. Rua José Rocha Junqueira, 13, Swift, 13045-755, Campinas, SP, Brasil. Correspondência para / Correspondence to: M SPERANDIO. E-mail: <Marcelo.sperandio@sImandic.edu.br>.

$\boldsymbol{\nabla} \boldsymbol{\nabla} \boldsymbol{v}$

Como citar estar artigo / How to cite this article

Farias SL, Silva MBF, Cardoso RJA, Sperandio M. Image-based study of marginal bone loss in teeth restored with cast endodontic posts. RGO, Rev Gaúch Odontol. 2018;66(4):353-359. http://dx.doi.org/10.1590/1981-863720180004000093522 


\section{INTRODUCTION}

Endodontic treatment encompasses several fundamental and interdependent steps that are key to treatment success. The final coronal restoration often requires support from intracanal posts, which in turn, could become a risk factor to the surrounding bone, since the post is unable to prevent coronal bacterial leakage, either alone or combined with a sealer $[1,2]$. Success of endodontic therapy depends on a high-quality coronal seal, whether provisional or definitive. Protection of the root fillings by an adequate coronal restoration is of utmost importance to maintain a successful endodontic outcome.

Katsamakis et al. [3] evaluated 146 complete sets of periapicals from patients with periodontal disease, and reported a greater marginal bone loss in 194 teeth restored with an intracanal post when compared with their cotralateral tooth. Additionally, their findings included the presence of angular bone defects in 18\% of post-restored teeth against $7.8 \%$ in their contralateral counterparts.

Cone beam computed tomography $(\mathrm{CBCT})$ is able to convert the pixels of a panoramic radiograph into voxels using dedicated software, which allows the visualization of superimposed images by simply rotating the main image or even checking a different 1-mm thick slice, or even to mount a 3D image having a like-for-like reproduction of the area studied [4].

$\mathrm{CBCT}$ could, therefore, consist in the radiographic imaging of choice in such scenarios due to its ability to eliminate overlaps that normally hinder image interpretation in two-dimensional takes [5].

The aim of this study was to evaluate marginal bone loss in patients with intacanal post-retained restorations, as per reported by Timmerman \& Weijden [6] and Katsamakis et al. [3], using sagittal and coronal slices from CBCT.

\section{METHODS}

This study was approved by the Research Ethics Committee of the Sao Leopoldo Mandic Dental School, under the registration number: 838 551. Data were obtained from the archives of the Sao Leopoldo Mandic Radiology Center, Campinas Campus. The study was based on a convenience sample of 2051 CBCT scans from patients that had been imaged for dental implants.

The inclusion criteria consisted primarily of singlerooted teeth restored with a cast metal post, regardless of their periodontal or endodontic status, with a standing contralateral tooth that did not show evidence of an intracanal retainer. Cases were excluded if the angulation of the teeth obscured the readings despite compensatory image slice adjustments, if caries, resorptions and/or fractures were detected.

The final sample population comprised 201 patients. The data were collected by a single examiner, specially trained and supervised by a radiology specialist using an image-based software (Xoran version 3.1.62, Xoran Technologies) installed to run an i-CATTM tomographic scanner (120 kVp, 36 mA, Imaging Sciences International, USA). A multiplanar reconstruction window was set up in which the axial, coronal and sagittal planes were evaluated at 0.2-mm intervals on an LED monitor configured for $1280 \times 1024$ of resolution. The image analysis was performed using the i-CAT ${ }^{\mathrm{TM}}$ software. In the coronal and sagittal CT slices, the most central slice of the tooth was chosen, or the next cut that allowed the best visualization of all dental structures of interest.

Patients were considered as having characteristic radiographic aspects of periodontal disease when they presented generalized horizontal bone loss on all aspects of at least four teeth [7].

Endodontic evaluation was based on the following parameters: quality of endodontic treatment (adequate or inadequate), presence of apical bone loss, marginal bone loss along the length of the root. The quality of the root filling was used as a surrogate marker for quality of the endodontic treatment and it was deemed adequate when a root filling was presented, not showing signs of voids and it extended to the apical limit of the root or approximately $1 \mathrm{~mm}$ short of the radiographic apex. It was otherwise classed as inadequate.

Bone loss was defined as the presence of any hypodense image in the region of the root periapex and/ or disruption of the lamina dura. For enhanced accuracy, these teeth were analyzed in both the sagittal and coronal slices. Marginal bone loss (mesial and distal) was evaluated on images from coronal slices, having the cementoenamel junction as reference. In the sagittal slices, bone loss was evaluated on the buccal and lingual surfaces.

Root measurements and scoring systems were modified from Müller \& Ulrich [8]. Briefly, the coronal slices (mesial and distal) and sagittal slices (buccal and lingual/ palatal) were taken from a fixed point at the root apex 
(point $A$ ) to the most cervical portion of the root or to the cementoenamel junction visible on the $\mathrm{CT}$ image (point $\mathrm{B}$ ) (figure 1) in millimeters. This same measurement was taken for the opposite side of the root on the same CT slice and this straight segment was named $A B$ (figure 1). The most apical point of the endodontic post was named point $C$ and the distance between that point and the apex was named segment $A C$ (figure 1). The value obtained for $A C$ was subtracted from the $A B$ value for each root surface: mesial, distal, buccal and lingual AB-AC (figure 1), which gave the length of the post within the root. Measurements of bone crest resorption were taken in a similar fashion using the point $\mathrm{A}$ to the maximum extent of bone attachment cervically (point $D$ ), generating an $A D$ segment (figure 1). Therefore, $A B-A D$ was used to assign a value $(\mathrm{mm})$ to the loss of bone crest height for the respective surfaces investigated.

In order to assess bone crest resorption in relation to the root length, a scoring system based on Müller \& Ulrich [8] was adapted for all aspects of the root investigated: mesial and distal (coronal plane), buccal and lingual (sagittal plane). The scores ranged from 1 to 5 , each of which represents $1 / 4$ of the root length, where 5 represented the score that exceeded $4 / 4$ of the measurement. For score 1 , a subscore was created, the score 0 , which had a fixed value of $1 \mathrm{~mm}$ and was used in those cases where $A B-A D$
$<1 \mathrm{~mm}$ and such cases were regarded as having no bone crest resorption.

The bone loss data $(\mathrm{mm})$ conformed to the assumptions of parametric testing upon removal of outliers and transformation by the square root, so that the Paired-t test was used to compare post and contralateral teeth. Non-parametric testing was also performed on the original non-transformed data using the Wilcoxon test to validate the parametric results. Chi-square test was applied to the scores. One-way ANOVA followed by Tukey's post hoc test were used to compare post length within the root canal. The significance level was set at $p<0.05$. The statistical calculations were performed on SPSS version 20.0 (IBM, USA) and GraphPad Prism version 6.0.

\section{RESULTS}

Regarding tomographic evidence of periodontal disease, whenever present, it was bilateral in our population sample, with no difference between the post-restored teeth and their contralaterals, where $49.8 \%$ of the patients showed signs of periodontal disease bilaterally, while $50.2 \%$ patients had no evidence of periodontal disease on CBCT (table 1).

Regarding quality of the endodontic treatment from the CBCT scans, $30.3 \%$ of the cases were found to

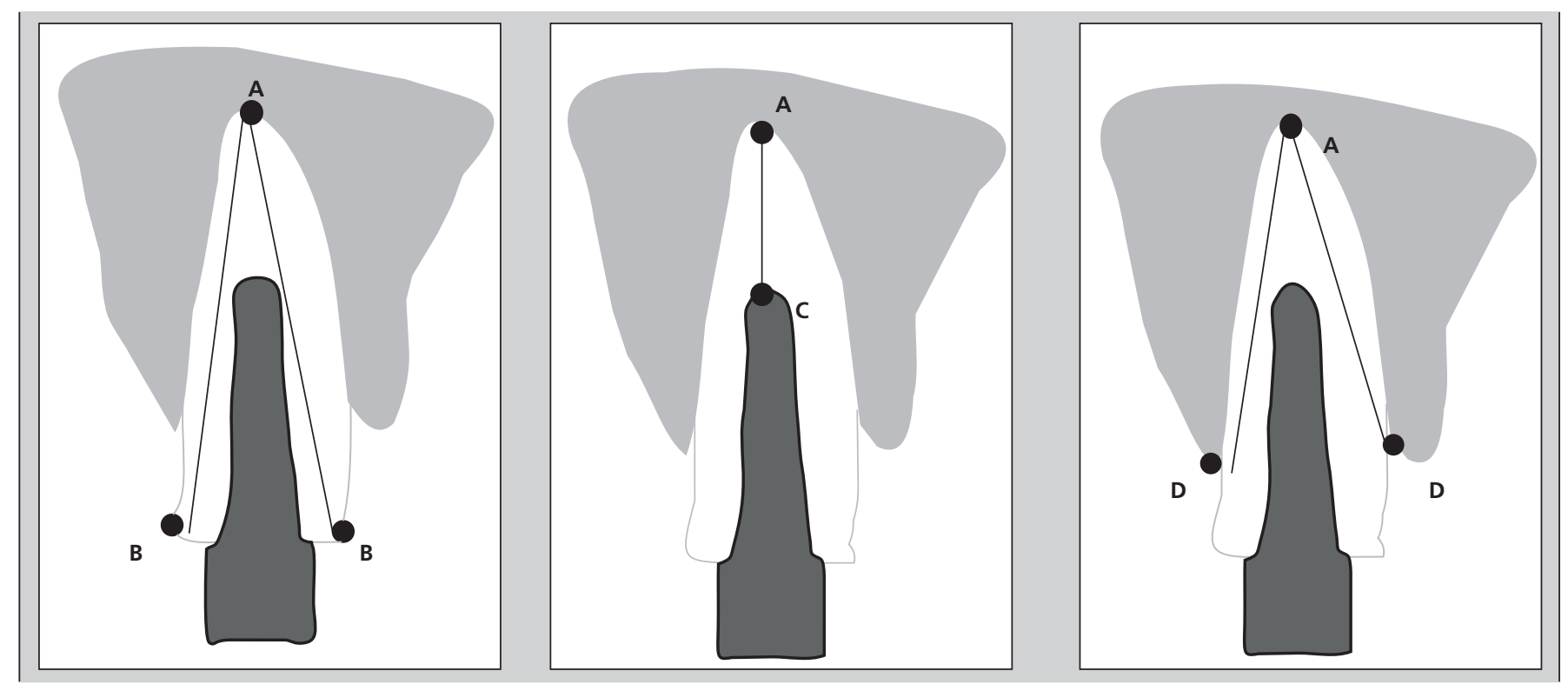

Figure 1. Illustration of the measurements taken for root length (RL), post length (PL) height of bone loss (BL) where: $R L=A B ; P L=A B-A C$ and $B L=A B-A D$. Adapted from Müller \& Ulrich 2005. 


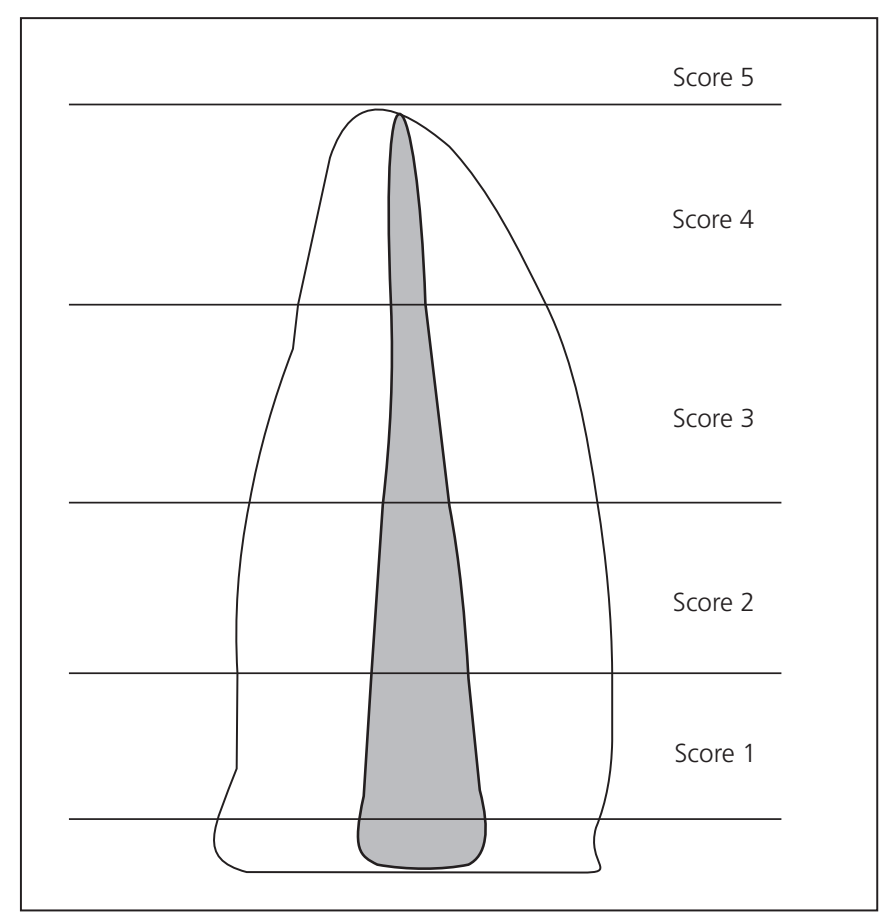

Figure 2. Bone loss score in relation to root length.

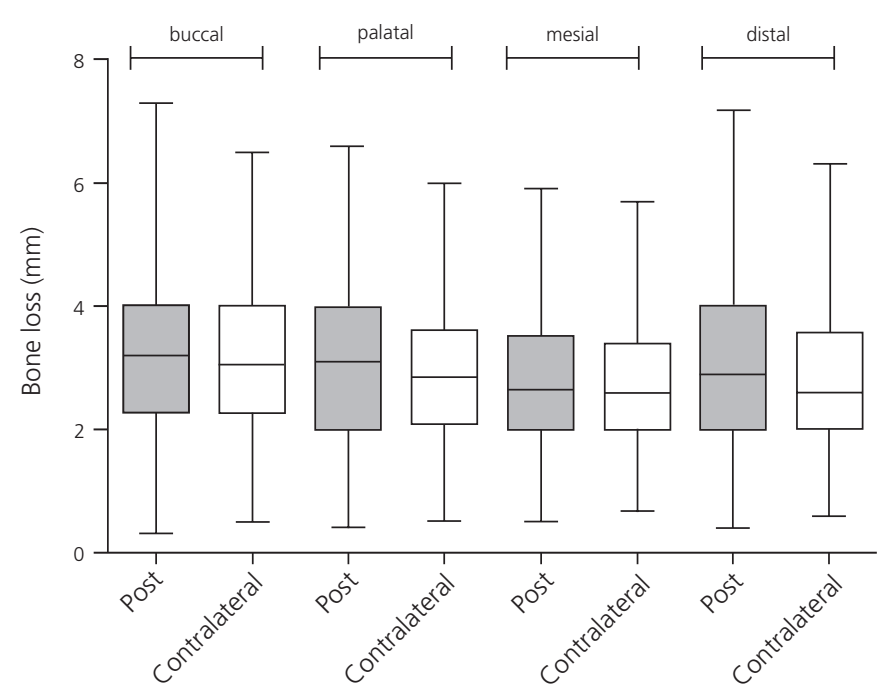

Figure 3. Mean ( \pm standard deviation) of bone crest loss (AB-AD) on the buccal aspect of the post-restored teeth and the contralateral teeth. No significant difference was identified by the Paired t test between the post-restored teeth and their contralaterals in terms of absolute bone loss $(\mathrm{mm})$. This approach does not take into account the length of the root.

be inadequate, whilst 140 cases (69.7\%) were regarded as adequate.

The 201 post-restored teeth showed image-based evidence of periapical changes in $40.3 \%(n=81)$ of the

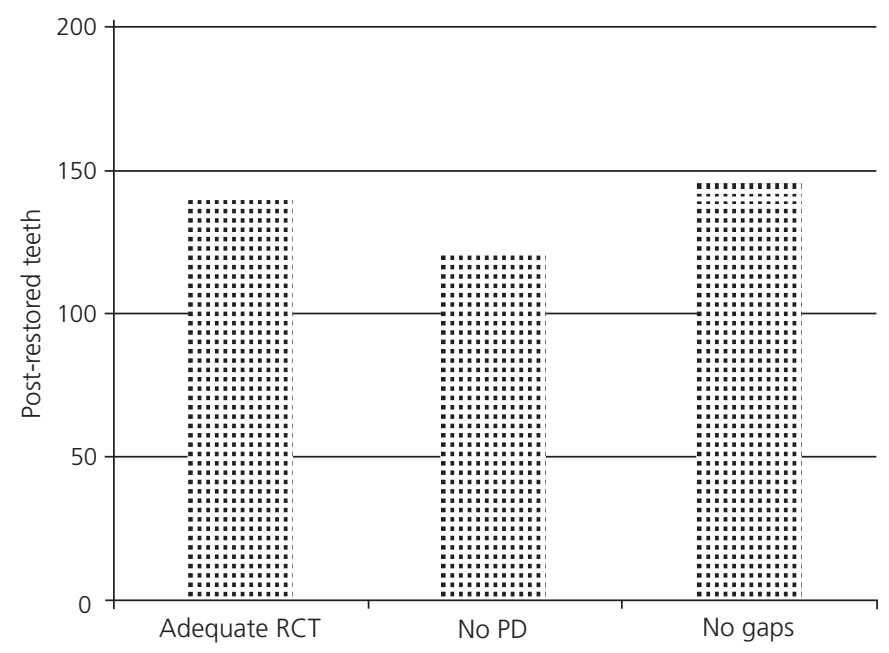

Figure 4. Distribution of the parameters of quality of the 201 post-restored teeth. RCT (root canal treatment), PD (periapical disturbance), no gaps (no voids between the post and the obturating material).

cases, whereas the remaining $59.7 \%(n=120)$ were free from periapical disease.

The average length of the intracanal posts ( $C A-A B)$ from the 201 cases on the buccal, lingual/palatal, mesial and distal aspects was $6.8 \mathrm{~mm}$ (SD 1.94). No significant difference was observed in mean post length between the 4 aspects analyzed (one-way ANOVA followed by Tukey tests, $p>0.05$ ), demonstrating accuracy of measurements across the 4 surfaces.

Bone crest resorption from coronal slices showed that on the buccal aspect the scores for the contralateral teeth ranged from 0 to 3, where the most frequent score was $1(n=128,63.7 \%)$, whereas for the post-restored teeth, the scores ranged from 0 to 5 and 102 cases (50.7\%) scored 1 . The Chi-square test did not reveal a significant association between the scores from the two groups on the buccal aspect ( $d f=15$, likelihood ratio $p=0.798$ ), demonstrating that the samples were independent from each other, where higher scores were observed in the postrestored group.

On the palatal aspect, both groups scored from 0 to 4 . For the contralateral teeth, the most frequent score was 1 (130 cases, 64.7\%) against 112 cases (55.7\%) in the post-restored group. As per the buccal aspect, the palatal surface revealed no association between the post and the contralateral groups ( $d f=16$, likelihood ratio $p=0.097$ ).

A similar picture was observed for the mesial aspect, where the post-restored groups scored between 
Table 1. Descriptive analysis of the post-restored teeth and the contralateral teeth in relation to their periodontal status.

\begin{tabular}{lccc}
\hline & No periodontal disease & Periodontal disease & Total \\
\hline Contralateral & $101(50.2 \%)$ & $100(49.8 \%)$ & 201 \\
Post-restored & $101(50.2 \%)$ & $100(49.8 \%)$ & 201 \\
& 202 & 200 & 402 \\
\hline
\end{tabular}

Table 2. Score distribution across the surfaces for the post-restored teeth and contralateral teeth for the Chi-squared test.

\begin{tabular}{|c|c|c|c|c|c|c|}
\hline Contralateral teeth & \multicolumn{6}{|c|}{ Post restored teeth } \\
\hline \multirow{3}{*}{ Score 0} & $0(B)$ & 4 & 2 & 1 & 0 & 0 \\
\hline & $0(\mathrm{M})$ & 1 & 2 & 0 & 0 & 0 \\
\hline & $0(\mathrm{D})$ & 7 & 3 & 0 & 0 & 0 \\
\hline \multirow{2}{*}{ Score 1} & $11(\mathrm{M})$ & 96 & 47 & 1 & 0 & 0 \\
\hline & $11(\mathrm{D})$ & 75 & 47 & 3 & 2 & 0 \\
\hline \multirow{3}{*}{ Score 2} & 2 (B) & 27 & 26 & 6 & 1 & 0 \\
\hline & $0(P)$ & 34 & 20 & 3 & 0 & 0 \\
\hline & $2(\mathrm{M})$ & 16 & 15 & 5 & 1 & 0 \\
\hline Score 3 & $0(\mathrm{D})$ & 1 & 0 & 1 & 0 & 0 \\
\hline \multirow{4}{*}{ Score 4} & $0(B)$ & 0 & 0 & 0 & 0 & 0 \\
\hline & $0(P)$ & 1 & 0 & 0 & 0 & 0 \\
\hline & $0(\mathrm{M})$ & 0 & 0 & 0 & 0 & 0 \\
\hline & $0(D)$ & 0 & 0 & 0 & 0 & 0 \\
\hline \multirow{4}{*}{ Score 5} & $0(B)$ & 0 & 0 & 0 & 0 & 0 \\
\hline & $0(P)$ & 0 & 0 & 0 & 0 & 0 \\
\hline & $0(\mathrm{M})$ & 0 & 0 & 0 & 0 & 0 \\
\hline & $0(\mathrm{D})$ & 0 & 0 & 0 & 0 & 0 \\
\hline
\end{tabular}

0 and 4 , while the contralateral teeth between 0 and 3 . The former had 155 cases scoring 1 (77.1\%), whereas the latter 116 (57.7\%). The chi-square test revealed no significant correlation between the two groups $(\mathrm{d} f=12$, likelihood ratio $\mathrm{p}=0.06$ ).

The distal aspect of the teeth was the only surface that showed a significant association between the two groups ( $d f=12$, likelihood ratio $p=0.008)$. In other words, the scores of bone loss at the distal aspect of the teeth were very similar in both groups.

When the absolute values of bone loss in millimeters were compared using the paired-T test, no significant differences were observed between the postrestored teeth and the contralateral teeth $(p>0.05)$.

\section{DISCUSSION}

Alveolar bone loss is one of the consequences of periodontitis and patients diagnosed with periodontal disease show a high rate of horizontal bone loss (92.2\%) and low rate of angular bony defects $[9,10]$, where the former has been reported to increase with age [8]. Periodontally compromised patients with endodontically treated teeth tend to show greater rates of bone loss when compared to their contralateral teeth $[6,9,10]$. It is therefore clear that bone loss may interfere with the longterm prognosis of endodontic treatment and, consequently, controlling bone loss with therapeutic interventions and/ or periodontal health maintenance is paramount for the 
success of the endodontic treatment and the longevity of a functional tooth.

Katsamakis et al. [3] reported higher bone loss in teeth restored with intracanal posts when compared to the non-post restored contralateral teeth, though such difference did not reach statistical significance, which may have been justified on the fact that 28 of the contralateral teeth had been endodontically treated and therefore may have influenced the outcome of their statistical analysis. In addition, and contrary to Müller \& Ulbrich [8], Katsamakis et al. [3] reported a higher rate of angular bony defects in the post-restored teeth than in the non-post restored contralateral teeth.

Using a scoring system to assess bone loss around a post-restored tooth against its contralateral counterpart, such as reported by Katsmakasis et al. [3] and the present study, permits objective measurements of bone loss, taking into account relevant aspects, such as the length of the roots. Absolute values, in millimeters, for instance, do not account for variations in root length, thus risking an underestimation of the defect (figure 3). Additionally, a split mouth approach carries the advantage of using the same patient as both test and control, thus capitalizing on several positive aspects, such as similarity of the local environment, equivalent occlusal forces and biofilm control pattern.

Patients with periodontal disease lose bone, thus exposing the cement surface and often the subjacent dentine. Bacteria can therefore infiltrate the dentinal tubules towards the pulp triggering odontoblasts to react in an attempt to protect the pulp, thus minimizing tissue damage [11]. Endodontically treated teeth, however, have lost this protective feature [12]. It is therefore inappropriate to suggest that bone loss is independent from the presence of root canal treatment, since it may have been caused by coronal leakage, dentinal permeability or even both [13-17].

Despite only using two-dimensional images, most studies in the literature point to greater bone loss in endodontically treated teeth when compared to their contralaterals. Timmerman \& Van der Weijden [6] reported bone loss of $4.2 \mathrm{~mm}$ mesially and $4.5 \mathrm{~mm}$ distally in endodontically treated teeth whilst $3.5 \mathrm{~mm}$ and $3.9 \mathrm{~mm}$, respectively, in the contralaterals. Additionally, Adyani-Fard et al. [9] reported $3.4 \mathrm{~mm}$ of bone loss in endodontically treated teeth and $3.23 \mathrm{~mm}$ in non-endodontically treated teeth, whilst the mean bone loss values reported by Deepak \& Sukla [18] were $4.3 \mathrm{~mm}$ and $3.7 \mathrm{~mm}$, respectively.
Regarding teeth with both root canal treatment and endodontic post, a trend to greater bone loss has been observed in relation to contralateral teeth. Further to their analysis on root canal treated teeth without a post retained restoration, Timmerman \& Van der Weijden [6] also investigated teeth with an endodontic post, with bone loss recorded at $4.3 \mathrm{~mm}$ both mesially and distally in the post-restored group against $3.3 \mathrm{~mm}$ and $4.0 \mathrm{~mm}$, respectively, in the contralaterals. Despite being part of the same group of researchers as Timmerman \& Van der Weijden [6], Katsamakis et al. [3] reported opposite findings, with greater loss in the contralateral teeth as apposed to the post-restored teeth, with measurements such as 3.9 $\mathrm{mm}$ mesially and $3.94 \mathrm{~mm}$ distally in teeth restored with a root canal post, whilst those without a post recorded $4.06 \mathrm{~mm}$ and $4.2 \mathrm{~mm}$ respectively, though not statistically significant. The findings from the present study corroborate the former reports regarding a trend towards greater loss in the post-restored teeth, however further analyses were performed on the 4 aspects of the teeth, in which the buccal and palatal/lingual aspects were also assessed. The palatal aspect recorded $3.20 \mathrm{~mm}$ and $3.08 \mathrm{~mm}$ in the post-restored and contralateral teeth, respectively, whereas buccally, the measurements were $3.56 \mathrm{~mm}$ and $3.22 \mathrm{~mm}$, respectively, thus illustrating a trend towards greater bone loss in teeth restored with endodontic cast posts. It was not possible to verify the findings for the buccal and palatal/lingual aspects against the literature, since this appears to be the first report using $C B C T$ to scrutinize all aspects of the teeth. All above-described studies used digital periapical images and dedicated software for their measurements, except for Timmerman \& Van der Weijden [6], who performed their measurements manually using conventional radiographs.

$C B C T$ is currently the highest precision imaging test in dental radiology. It provides clear views from all aspects of the teeth in three planes, sagittal, coronal and axial. It yields reliable diagnostic data from the periapex, roots, root canal anatomy, instrument and root fractures, root/bone resorption, etc. $[19,20]$. CBCT was crucial in establishing differences in bone loss in this study, since the most significant sites between the test (post-restored) and the control (contralateral) groups were the buccal and palatal aspects of the teeth $(p=0.798$ and $p=0.097$, respectively), which could not have been visualized using conventional two-dimensional imaging techniques such as interproximal or periapical radiographs. 
The findings from this study suggest that the presence of a cast endodontic post may have a deleterious effect on the periodontium. This raises some important questions regarding the possible pathogenesis of bone loss, such as biomechanical imbalances or even post maladjustments within the root canal, possibly inducing micro cracks both cervically or along the root surface, thus compromising periodontal health and eventually leading to irreversible loss of function. It is therefore essential to encourage multidisciplinary investigations on endo-periorestorative interactions in order to ameliorate the success rates of such dental rehabilitations, safeguarding sound tooth structure from extensive mutilation and excessively invasive procedures.

\section{Collaborators}

SL FARIAS, concept, study design, data collection, MBF SILVA, concept, data analysis and manuscript review. RJA CARDOSO, concept, study design and manuscript review. M SPERANDIO, data analysis, manuscript write-up, manuscript review.

\section{REFERENCES}

1. Cardoso RJA. Avaliação "in vitro" da qualidade do vedamento marginal cérvico-apical de alguns agentes cimentantes utilizados na fixação de um retentor intra-radicular préfabricado (CYTCO) [tese]. São Paulo: Universidade de São Paulo; 1994.

2. Ravanshad BS, Torabinejad, M. Coronal dye penetration of the apical filling materials after post space preparation. Oral Surg Oral Med Oral Pathol. 2003;74(5):644-7.

3. Katsamakis S, Timmerman MF, van der Velden U, de Cleen MJH, van der Weijden F. Patterns of bone loss around teeth restored with endodontic posts. J Clin Periodontol. 2009;36(11):940-9. https://doi.org/10.1111/j.1600-051X.2009.01465.x

4. Khayat B, Michonneau JC. Evaluate cone beam imaging technology in endodontics. Endodontic Pract. 2009;45:44-8.

5. Evered JS, Webb T. Cone beam computed tomography ind endodontics. Naval Postgraduate Dent Sch. 2009;1-2.

6. Timmerman MF, Van der Weijden GA. Bone level around endodontically treated teeth in periodontitis patients. J Clin Periodontol 2006;33(9):620-5.

7. Corbet EF, Ho DKL, Lai SLM. Radiographs in periodontal disease diagnosis and management. Aust Dent J. 2009;54(Suppl 1):S27-43. https://doi.org/10.1111/j.1834-7819.2009.01 141.x
8. Müller HP, Ulbrich M. Alveolar bone levels in adults as assessed on panoramic radiographs. (I) Prevalence, extent, and severity of even and angular bone loss. Clin Oral Investig. 2005;9(2):98-104.

9. Adyani-Fard D, Kim T-S, Eickholz P. Interproximal bone loss at contra-lateral teeth with and without root canal filling in periodontitis patients. J Clin Periodontol. 2011;38(3):269-75. https://doi.org/10.1111/j.1600-051X.2010.01657.x

10. Jayakumar A, Rohini S, Naveen A, Haritha A, Reddy K. Horizontal alveolar bone loss: A periodontal orphan. J Indian Soc Periodontol. 2010;14(3):181-5. https://doi.org/10.410 3/0972-124X.75914

11. Love RM, Jenkinson HF. Invasion of dentinal tubules by oral bacteria. Crit Rev Oral Biol Med. 2002;13(2):171-83.

12. Adriaens PA, De Boever JA, Loesche WJ. Bacterial invasion in root cementum and radicular dentin of periodontally diseased teeth in humans. J Periodontol. 1988;59(4):222-30.

13. Saleh IM, Ruyter IE, Haapasalo M, Ørstavik D. Bacterial penetration along different root canal filling materials in the presence or absence of smear layer. Int Endod J. 2008;41(1):32-40.

14. Oliveira SGD, Gomes DJ, Costa MHN, Sousa ER, Lund RG Coronal microleakage of endodontically treated teeth with intracanal post exposed to fresh human saliva. J Appl Oral Sci. 2013 Sep-Oct;21(5):403-8. https://doi.org/10.1590/1679775720130184

15. Gillen BM, Looney SW, Gu L, Loushine BA, Weller RN, Loushine RJ, et al. Impact of the quality of coronal restoration versus the quality of root canal fillings on success of root canal treatment: a systematic review and meta-analysis. J Endod. 2011;37(7):895-902. https://doi.org/10.1016/j. joen.2011.04.002

16. Wu MK, Pehlivan Y, Kontakiotis E G, Wesselink PR Microleakage along apical root fillings and cemented posts. J Prosthet Dent 1998;79(3):264-9.

17. Ricucci D, Bergenholtz G. Bacterial status in root-filled teeth exposed to the oral environment by loss of restoration and fracture or caries - a histobacteriological study of treated cases. Int Endod J. 2003;36(11):787-802.

18. Deepak D, Dara S. Bone levels around endodontically treated teeth in periodontitis patients. Guidentet. 2012;66-70.

19. Nesari R, Rossman LE, Kratchman SI. Cone-beam computed tomography in endodontics: are we there yet? Compend Contin Educ Dent. 2009;30(6):312-8.

20. Scarfe WC, Levin MD, Gane D, Farman AG. Use of cone beam computed tomography in endodontics. Int J Dent. 2009;2009:634567

Received on: 1/12/2017

Final version resubmitted on: 5/5/2018

Approved on: 25/5/2018 